\title{
Valorization of underutilized river tamarind Leucaena leucocephala seeds biomass for cellulose nanocrystals synthesis
}

\author{
Maryam Husin ${ }^{1}$, Zul Ilham ${ }^{2}$ *, Abd Rashid Li ${ }^{3}$, Atik Zufar Mohd Razaki ${ }^{2}$, Wan Abd Al Qadr Imad Wan-Mohtar ${ }^{2}$, \\ Salbiah $\operatorname{Man}^{3}$
}

${ }^{1}$ Faculty of Applied Sciences, Universiti Teknologi MARA, Shah Alam, Malaysia

2Institute of Biological Sciences, Faculty of Science, University of Malaya, Kuala Lumpur, Malaysia

${ }^{3}$ Forest Research Institute Malaysia (FRIM), Kuala Lumpur, Malaysia

\section{A R T I CLE IN F O}

\section{Article history:}

Received 6 May 2020

Received in revised form

1 September 2020

Accepted 3 September 2020

\section{Keywords:}

Leucaena leucocephala

Cellulose

Nanocrystals

Acid hydrolysis

Agricultural waste

\begin{abstract}
A B S T R A C T
River tamarind or scientifically Leucaena leucocephala, is one of the underutilized nanocellulose resources with the potential to be used in reinforcement materials. This work evaluated the use of the insoluble residual waste or marc obtained during the isolation of galactomannan from Leucaena leucocephala seed (LLS) as a feedstock of cellulose to obtain cellulose nanocrystals by a two-step acid hydrolysis followed by its characterization and morphological study. The first step involved acid hydrolyzation of the hemicellulose and lignin from LLS, while the second step dealt with the removal of the amorphous region to produce crystalline LLS nanocrystals (NLLS). The physicochemical properties of nanocrystals were characterized using the Fourier transform infrared spectroscopy (FTIR), field emission scanning electron microscopy (FESEM), transmission electron microscopy (TEM), particle size analyzer (PSA), X-ray diffractometer (XRD), thermal gravimetric analysis (TGA), and gel permeation chromatography (GPC). The NLLS isolated showed a rod-like structure in the range of 70$90 \mathrm{~nm}$ in diameter with a crystallinity index of $76 \%$ and thermal stability at $264^{\circ} \mathrm{C}$. PSA indicates that $97.5 \%$ of the size distribution of NLLS was below $136.9 \mathrm{~nm}$. GPC analysis also revealed that the sulphuric acid hydrolyzation during the second step caused a reduction in the molecular weight due to the cleaving of glycosidic bonds in the structure. These results indicated that LLS waste is a potential feedstock for cellulose nanocrystals preparation.
\end{abstract}

(C) 2020 The Authors. Published by IASE. This is an open access article under the CC BY-NC-ND license (http://creativecommons.org/licenses/by-nc-nd/4.0/).

\section{Introduction}

Nanocellulose is a nano-sized cellulosic material that has been widely studied in numerous fields, including in the pharmaceutical, textile, and biomaterial industries due to its interesting physical and chemical properties (Othman, 2014; Lin and Dufresne, 2014; Ilham and Nimme, 2019). For instance, nanocellulose is known to be biodegradable, biocompatible, has a high specific modulus and stability in most solvents, and low cytotoxicity. These allow it to be utilized as a polymer matrix, electrical materials for energy storage, and drug delivery (Jorfi and Foster, 2015; Chen and $\mathrm{Hu}, 2018)$. Nanocellulose is derived from

\section{* Corresponding Author.}

Email Address: ilham@um.edu.my (Z. Ilham) https://doi.org/10.21833/ijaas.2021.01.012

(D) Corresponding author's ORCID profile:

https://orcid.org/0000-0003-3836-0848

2313-626X/C) 2020 The Authors. Published by IASE.

This is an open access article under the CC BY-NC-ND license

(http://creativecommons.org/licenses/by-nc-nd/4.0/) the crystalline and amorphous regions of cellulose through various methods. Depending on the type of the lignocellulosic materials used, and the methods employed, the physicochemical properties of the nanocellulose can be altered (Khalil et al., 2014). These include the types of acid used for hydrolysis and the preparation techniques. There are two types of nanocellulose, which are cellulose nanocrystals (CNC) and cellulose nanofibrils (CNF).

Cellulose nanocrystals (CNC) are rod-like or needle-like cellulose crystals, ranging from the 5$70 \mathrm{~nm}$ diameter and $100-250 \mathrm{~nm}$ in length. They are produced from the hydrolyzation with strong acid to remove the non-cellulosic components and most amorphous cellulose, which resulted in a nearperfect crystallinity (Abitbol et al., 2016). On the contrary, cellulose nanofibrils (CNF) are long and entangled fibrils, have a high aspect ratio, and flexible (Abitbol et al., 2016). They appear as a highly viscous suspension at low concentration due to the clumping of the long fibers. They are generated through the exertion of high pressure before and/or 
after chemical or enzymatic treatment on the cellulose.

Different types of acids used in producing nanocellulose will influence the properties of the nanocellulose formed. For example, nanocellulose produced from sulphuric acid shows poor thermostability due to the presence of sulfate groups, which results in a negatively charged surface. Nonetheless, the colloidal suspension of the sulphuric acid-treated nanocellulose is more stable compared to those prepared with hydrochloric acid (Bano and Negi, 2017; Fahma et al., 2010).

In recent years, there has been a significant interest in the extraction of cellulose nanocrystals from various sources. Nanocellulose isolation normally involves three important steps: (1) extraction with an organic solvent removal of fats, oils, resins, and waxes, (2) bleaching for delignification, and (3) treatment with a strong alkaline solution to remove hemicellulose. Many pretreatment processes have been reported for cellulose isolation, such as pulping, grinding, and acid hydrolysis (Abitbol et al., 2016).

Pretreatment methods are employed to disrupt the structure to aid in the removal of lignin, hemicellulose, and other lignocellulosic materials. Bleaching and alkali treatment help in isolating cellulose nanocrystals. (Rabemanolontsoa and Saka, 2016; Kim et al., 2016). However, this method is associated with a low yield of cellulose, timeconsuming, and involves repetitive bleaching. Bleaching uses sodium chloride, which produces toxic chlorinated compounds as by-products and is harmful to the environment (Karimi and Taherzadeh, 2016).

This study aimed to extract cellulose nanocrystals from the insoluble residual waste or marc obtained during the isolation of galactomannan from mature seeds of Leucaena leucocephala (LLS). In Malaysia, LLS is commonly known as Petai Belalang. Other names include river tamarind, lead tree, white leadtree, white popinac, wild tamarind, kubabul, subabul, ipil ipil, kariskis, palo-maria faux mimosa, kladingan, lamtoro, tagarai krathin, and tobao. It can be found abundant throughout Malaysia and is underutilized, making it a sustainable source.

A two-step acid hydrolysis process was employed in extracting the cellulose nanocrystals from LLS. A mixture of acetic acid and nitric acid was used to aid in the fragmentation of hemicellulose and lignin in LLS. This saves time and reduces the amount of cellulose lost to the process. Next, LLS was treated with sulphuric acid to extract the cellulose nanocrystals. To date, no research has been reported on the preparation of cellulose nanocrystals from LLS by using these methods. The properties and characteristics of the cellulose nanocrystals were evaluated using the FTIR, FESEM, TEM, XRD, PSA, GPC, and TGA. Since cellulose nanocrystals have distinct properties, optimizing LLS cellulose nanocrystals to be used in industrial applications can be beneficial.

\section{Experimental and methods}

\subsection{Cellulose and nano cellulose preparation}

Chemical compositions (cellulose, hemicelluloses, and lignin) were determined according to the methods reported by the Technical Association of Pulp and Paper Industry (TAPPI) (Brendel et al., 2000). The insoluble residual waste or marc of LLS was obtained based on Rahim et al. (2018). The extraction of LLS cellulose was adopted from Husin et al. (2017). Briefly, the dried LLS was treated with a mixture of $80 \%$ of acetic acid and $65 \%$ of the nitric acid solution for 1 hour at $90^{\circ} \mathrm{C}$.

The cellulose nanocrystals were prepared as described by Jiang and Hsieh (2015). 10g of cellulose was hydrolyzed in $64 \% \mathrm{H}_{2} \mathrm{SO}_{4}$ (96\% purity) solution with an acid (fiber/acid ratio of $1: 10$ ) at $50^{\circ} \mathrm{C}$ under vigorous agitation for $60 \mathrm{~min}$. One liter of cold water was added to the reaction mixture to form cellulose nanocrystals suspension. The suspension was then rotated at $10,000 \mathrm{rpm}$ for $10 \mathrm{~min}$ to form precipitation. The process was repeated until the suspension reached $\mathrm{pH}$ 6. Next, dialysis was performed (3,000 Molecular Weight Cut Off) until the $\mathrm{pH}$ reached neutral.

\subsection{Characterization}

The soluble cellulose and cellulose nanocrystals were prepared based on Han et al. (2008) with slight modifications. Two solutions were prepared; (A) $6 \mathrm{~g}$ of dried LLS cellulose nanocrystals dissolved in $100 \mathrm{ml}$ of $\mathrm{Me}_{2} \mathrm{SO}$ containing $48 \mathrm{~g}$ of urea (8 M) and (B) $100 \mathrm{ml}$ of $\mathrm{Me}_{2} \mathrm{SO}$ mixed with $10 \mathrm{ml}$ of concentrated $\mathrm{H}_{2} \mathrm{SO}_{4}$ heated in a water bath at $100^{\circ} \mathrm{C}$. Next, solution A was added dropwise to solution B for 6 hours with stirring to form cellulose sulfate nanocrystals solution.

The solution was then diluted in 2 liters of deionized water and dialyzed for 5 days to remove any unreacted microparticulate cellulose. The cellulose sulfate nanocrystals extracted were collected and dried at room temperature. A scanning electron microscope (JEOL JSM-7600F) was used to observe the morphology of the LLS nanocrystals. The nanocrystals were mounted on aluminum stubs with carbon tapes, and the accelerating voltage was set at $10 \mathrm{kV}$. A transmission electron microscope (LIBRA 120 , Germany) with an acceleration voltage of $120 \mathrm{kV}$ was used to determine the dimensions of the nanocrystals. A drop of a diluted suspension of the cellulose nanocrystals (1wt.\%) was deposited on the surface of a carbon-coated $\mathrm{Cu}$ grid. The dimensions of the cellulose nanocrystals were determined using digital image analyses (Image J). Around 30-50 individual nanocrystals were randomly selected to determine its average length and diameter, respectively.

The identification of the chemical properties of the nanocrystals was made by using the Fourier transform infrared spectroscopy (FTIR). Ultrathin pellets were prepared by mixing $2 \mathrm{mg}$ of nanocrystals 
with potassium bromide, $\mathrm{KBr}$ powder and were tested in the range of $450-4500 \mathrm{~cm}^{-1}$ to obtain their IR spectra (Perkin-Elmer Spectrum 100IR spectrophotometer). A Netzsch thermogravimetric analyzer (TG209 F3 Tarsus model) was used to study the thermal behavior of the nanocrystals. $10.0 \pm 1.0 \mathrm{mg}$ of nanocrystals was subjected to varying temperatures ranging from $30-600^{\circ} \mathrm{C}$ at a rate of $10^{\circ} \mathrm{C} / \mathrm{min}$ under a nitrogenic atmosphere with a gas flow of $80 \mathrm{~cm}^{3} / \mathrm{min}$. Particle size was measured by dynamic light scattering (DLS, Zetasizer Nano S90, and Malvern).

The crystallinity of the nanocrystals was analyzed by using an X-ray diffractometer (X'Pert PRO MD PANalytical) with $\mathrm{CuK} \alpha$ radiation at $35 \mathrm{kV}$ and $30 \mathrm{~mA}$. The crystallinity index was calculated as described by Segal et al. (1959). The molecular weights of the cellulose and cellulose nanocrystals were determined by gel permeation chromatography (GPC). A standard calibration curve was prepared by dissolving $2 \mathrm{mg}$ of dextran in $2 \mathrm{ml}$ of distilled water. The molecular weights of the cellulose and cellulose nanocrystals were determined from the dextran standard calibration curve (molecular weight of dextran standards versus elution time).

\section{Results and discussion}

\subsection{Hemicellulose and cellulose contents}

The LLS contained $37.4 \pm 1.8$ of cellulose, $30.6 \pm 1.5 \%$ of hemicellulose, and $16.1 \pm 2.3 \%$ of lignin. LLS cellulose nanocrystals yield was low at $27 \%$, probably owing to the excessive degradation following sulphuric acid treatment. Xie et al. (2018) reported on the lower cellulose nanocrystals yield $(<30 \%)$ isolated through sulphuric acid hydrolysis (Xie et al., 2018). However, Chen et al. (2016) stated that decreasing the concentration of sulphuric acid and prolonging the reaction could help increase the yield of cellulose nanocrystals. LLS has a higher cellulose content compared to the melon seed shell (16.5\%) but lower than the mango seed (55\%) (Lu et al., 2016; Pius et al., 2014).

\subsection{Morphological structure of cellulose nanocrystals}

FESEM micrographs in Fig. 1 show the structure of the cellulose nanocrystals after the sulphuric acid hydrolyzation. The cellulose nanocrystals were negatively stained due to the conjugation of sulphuric acid moieties during the hydrolyzation. It can be observed that the nanocrystals are rod-like in shape, smaller in size and diameter (Fig. 1a), and tend to be in a cluster formation (Fig. 1b).

TEM images for the LLS cellulose nanocrystals (Fig. 2) observed individual long fibers with diameter ranges from $2-11 \mathrm{~nm}$. Since it is hard to discern the ends of the fibers in the bundles, an accurate estimation of their length could not be determined. It was estimated that the length of the fibers is $200 \mathrm{~nm}-300 \mathrm{~nm}$ in length. The nanocellulose fibers were seen to be laterally aggregated in clumps that formed a network due to a high specific area and strong hydrogen bonds interactions between the fibers (Henrique et al., 2013). Similar arrangements have been shown in the Isora nanofibrils and nanocrystals of mango seed, tomato peel, and banana peel (Chirayil et al., 2014; Pius et al., 2014; Jiang and Hsieh, 2015).

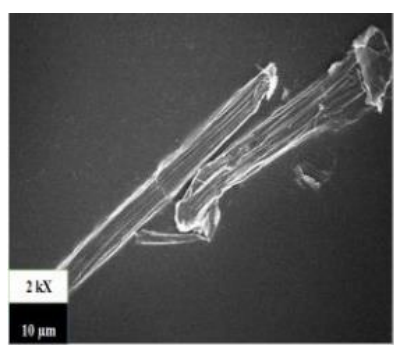

(a)

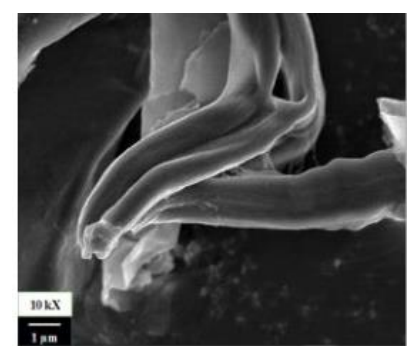

(b)
Fig. 1: Scanning electron micrograph (a) individual particle of cellulose nanocrystals (b) agglomeration of cellulose nanocrystals
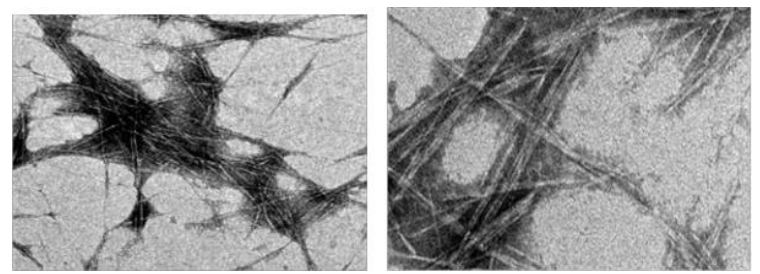

Fig. 2: Transmission electron micrograph of LLS (cellulose nanocrystals)

The aspect ratio of the nanocrystals was calculated to be between 70-90, which is considerably high. Cellulose nanocrystals with a high aspect ratio typically have high reinforcement ability (George and Sabapathi, 2015). This makes LLS nanocrystals suitable to be used as a reinforcement material in biocomposites in improving their mechanical strength. NLLS cellulose nanocrystals clusters were found to be distributed in two sizes (Fig. 3). $97.5 \%$ of the particles were $136.9 \mathrm{~nm}$, and $2.5 \%$ were about $4302 \mathrm{~nm}$. Tibolla et al. (2017) saw similar observations in the acid hydrolysis isolation of cellulose nanoparticles from other sources. However, the particle size distributions of the LLS nanocrystals are different from the TEM results. Nanocellulose has a long rod-like shape, and its diameter varies from $10 \mathrm{~nm}$ to $80 \mathrm{~nm}$, whereby its length ranges from $100 \mathrm{~nm}$ to $1000 \mathrm{~nm}$ (Henrique et al., 2013; Pius et al., 2014).

\subsection{FTIR spectra of cellulose nanocrystals}

Fig. 4 illustrates the FTIR spectra of nanocellulose-LLS (NLLS) and cellulose-LLS (CLLS). From Fig. 4, it can be seen that CLLS has two absorption peaks at $1730 \mathrm{~cm}^{-1}$ and $1551 \mathrm{~cm}^{-1}$. This is due to the $\mathrm{C}=\mathrm{O}$ and $\mathrm{C}=\mathrm{C}$ stretching in the acetyl and uronic ester groups of lignin and/or hemicellulose (Mendes et al., 2015). No absorption was found in NLLS in these regions, indicating the absence of hemicellulose and lignin in the structure. However, 
NLSS showed absorbance at $1203 \mathrm{~cm}^{-1}$, owing to the vibration of the $S=0$ sulphuric acid moieties on the

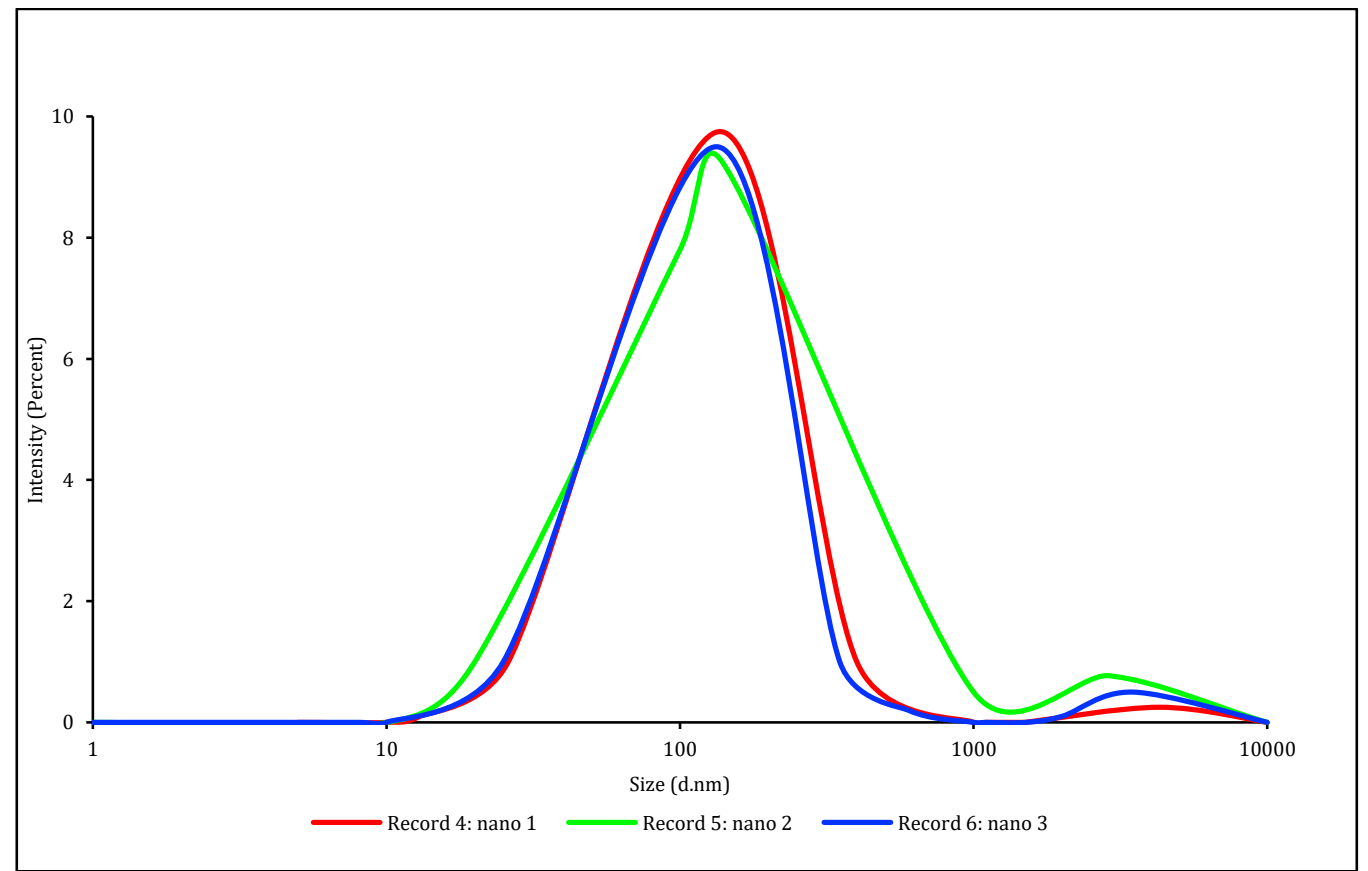

Fig. 3: Particle size distribution of cellulose nanocrystals

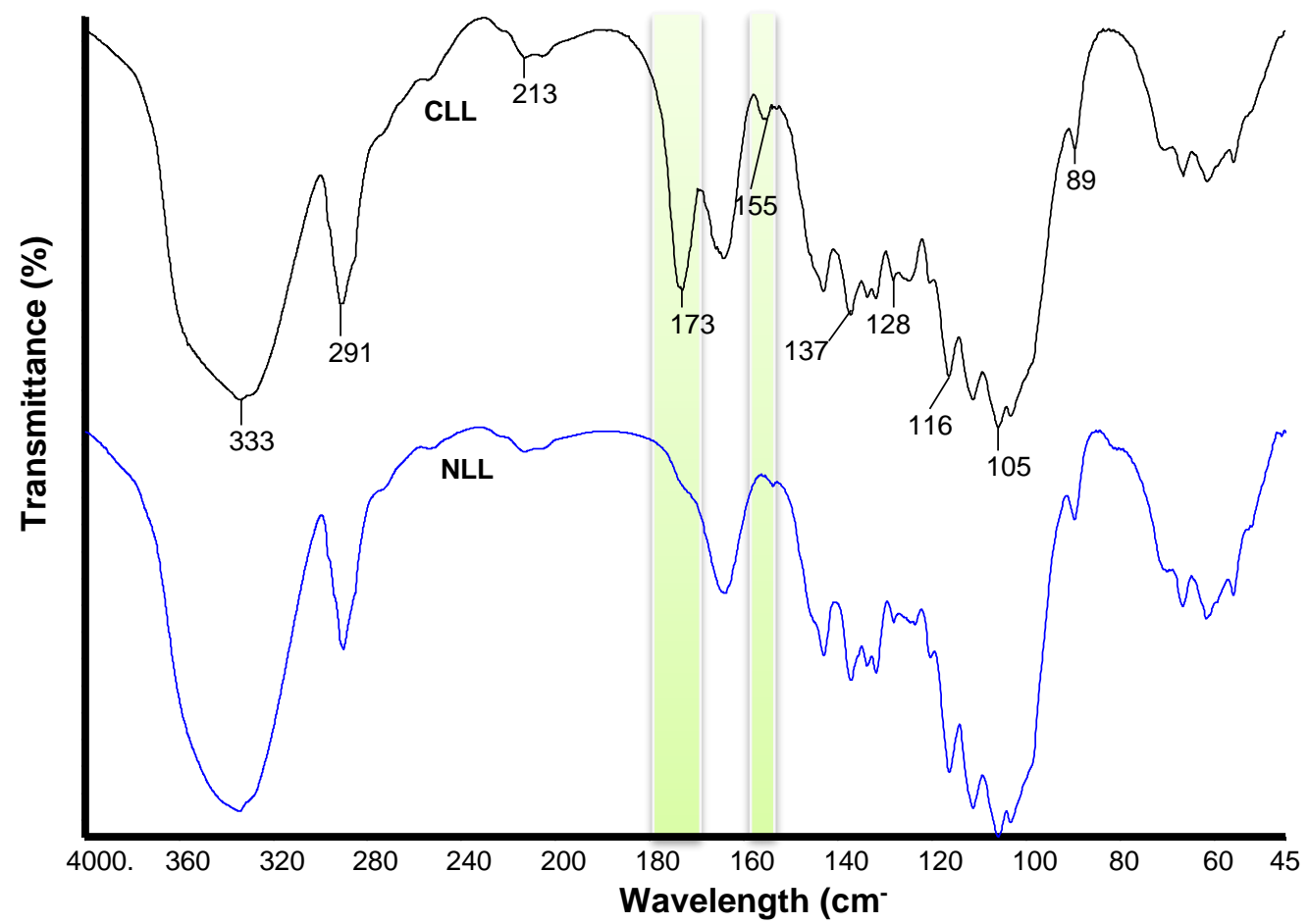

Fig. 4: FTIR spectra of NLLS in comparison with CLLS

\subsection{Thermal behavior}

The properties of NLLS and CLLS under thermal decomposition were shown in Fig. 5. Thermal decomposition of both celluloses involves the vaporization and removal of bound water from the structure. In both structures, a small weight loss was observed at $30^{\circ} \mathrm{C}-100^{\circ} \mathrm{C}$, which can be attributed to the removal of residual water from the celluloses. At $320.8^{\circ} \mathrm{C}$, CLLS was found to have the highest weight loss indicating maximum decomposition. In contrast, NLLS was seen to decompose at a lower temperature at $273.6^{\circ} \mathrm{C}$ due to the presence of sulfate group moieties on the surface of the structure. Smyth et al. (2017) stated that the thermostability of cellulose nanocrystals tend to decrease with higher sulfate groups content. Hence, NLLS needed less activation energy is to breakdown its structure (Morais et al., 2013). Jiang and Hsieh (2015) reported a similar finding on the isolation of nanocellulose from tomato peels. At $600^{\circ} \mathrm{C}$, NLLS (17.26wt\%) was observed to retain more weight compared to CLLS (12.80wt\%). This might be attributed to the higher crystallinity of 
NLLS, which made it flame resistant at high temperatures (Chirayil et al., 2014).

García et al. (2016) indicated that high crystallinities are associated with high thermal degradation. Mandal and Chakrabarty (2011) showed nanocomposites consisted of nanocellulose composites (NCC) have better resistance towards thermal degradation. The addition of NCC reinforces the interaction in the matrix through hydrogen bonding, which increases the thermal energy needed to break the bonds (Mandal and Chakrabarty, 2011). Consequently, this improves the thermal stability of the NCC.

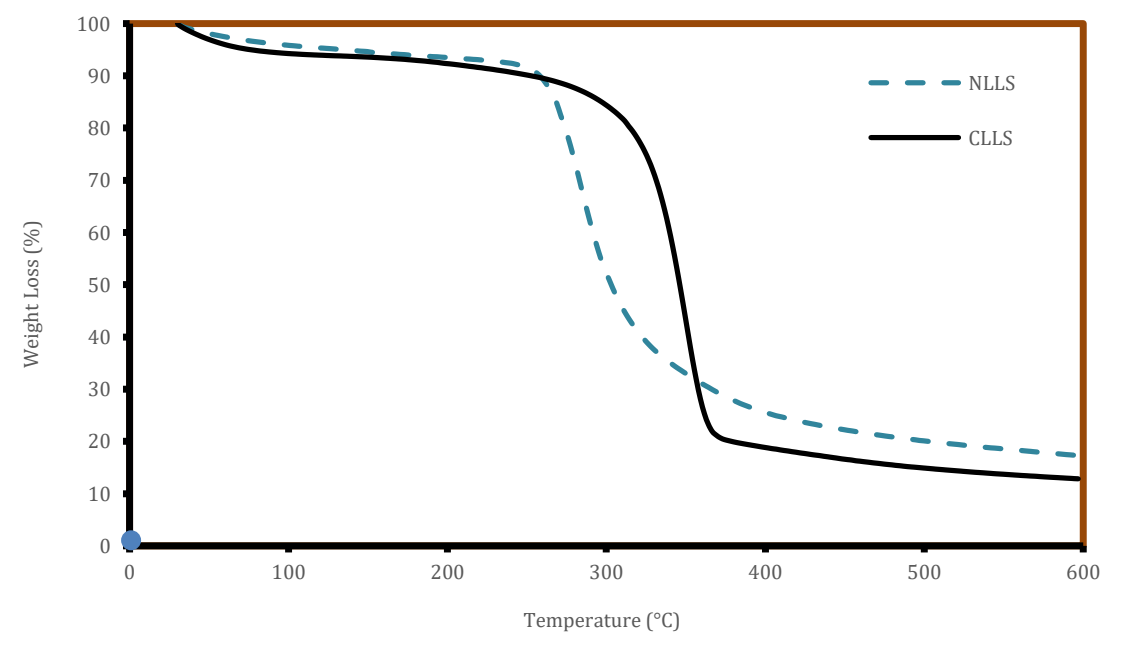

(a)

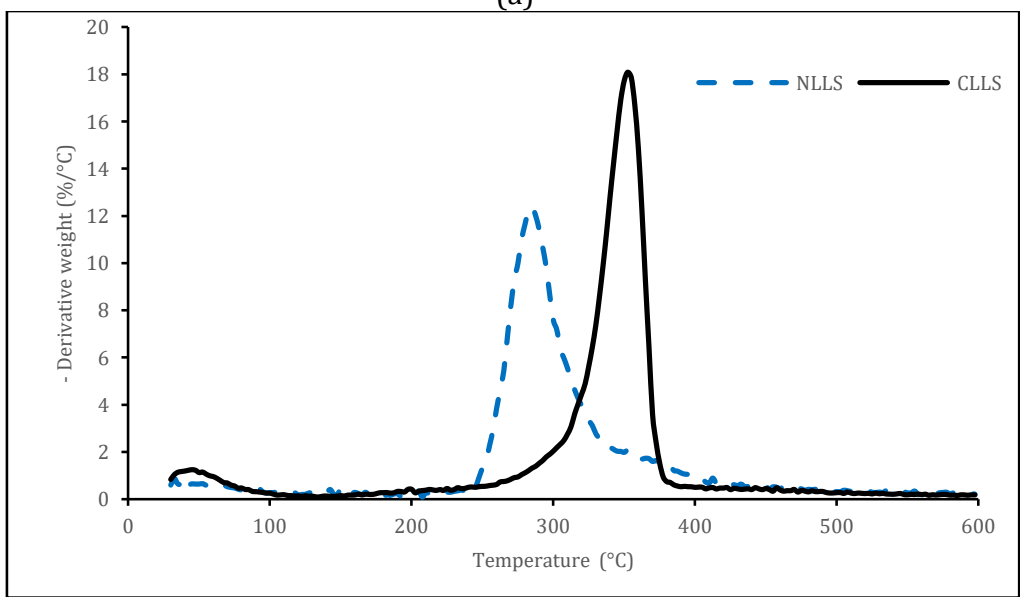

(b)

Fig. 5: Comparison of (a) TG and (b) DTG curves of cellulose and cellulose nanocrystals

\subsection{Crystallinity index of the cellulose nanocrystals}

The diffractograms for CLLS and NLLS (Fig. 6) showed that both celluloses peaked at $2 \theta=18.2^{\circ}$ and $22.6^{\circ}$, respectively. These peaks are common for cellulose type 1. Sèbe et al. (2012) showed the typical peaks for cellulose were at $15.7^{\circ}$ and $22.6^{\circ}$. The crystallinity index of CLLS (57.5\%) was found to be lower than that of NLLS (75.9\%). Higher crystallinity index in NLLS indicates that the treatment of sulphuric acid was able to remove the residual hemicellulose and lignin in the cellulose structure, leaving only the crystalline parts intact. High crystallinity nanocrystals are more firm and rigid, which makes it suitable to be used as nanocomposites in reinforcement materials. Marett et al. (2017) reported that an additional $5 \mathrm{wt} \%$ of CNCs isolated from pistachio shells in a TPU composite increased its modulus elasticity, providing higher yield stress in the composite.

LLS cellulose nanocrystals were also shown to have a higher crystallinity index compared to the nanocrystals isolated from pomelo waste $(60.3 \%)$, sweet potato residue $(72.5 \%)$, and coconut husk (65.9\%) (García et al., 2016). Haafiz et al. (2014) and Chirayil et al. (2014) observed a higher crystallinity index in nanocrystals isolated from oil palm biomass $(88 \%)$ and isora fiber (90\%). Nevertheless, the crystallinity index of nanocrystals is highly dependent on the techniques employed throughout the extraction process. Cherian et al. (2008) and Husin et al. (2019) saw a range of crystallinities (74\%-91\%) for the nanocrystals isolated from banana fibers and medicinal cotton by changing the pretreatments for cellulose pulping. Li et al. (2009) stated that the parallel rearrangement and growth of the monocrystals of the cellulose nanocrystals during the preparation might improve its 
crystallinity. Details on the crystallinity index and thermal stability of various nanocellulose resources are depicted in Table 1.

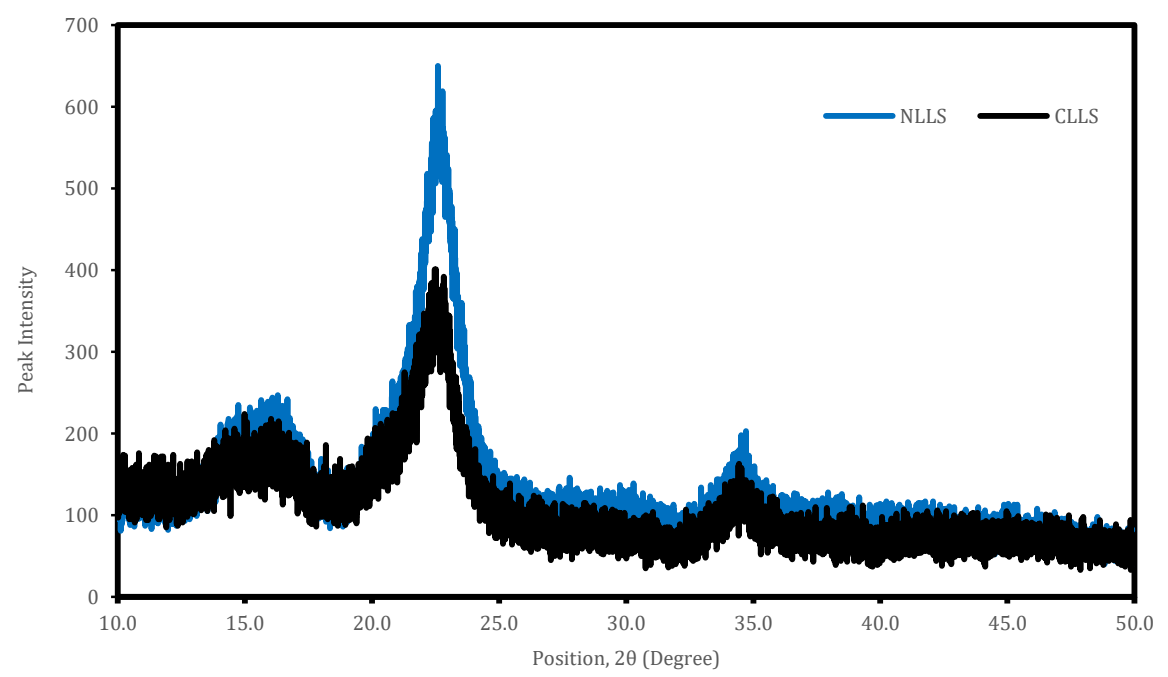

Fig. 6: XRD patterns of (a) cellulose (CLLS) and (b) cellulose nanocrystals (NLLS)

Table 1: Crytallinity index and thermal stability of various nanocellulose resources

\begin{tabular}{ccccc}
\hline & Nanocellulose Resources & Crystallinity Index (\%) & Thermal Stability $\left({ }^{\circ} \mathrm{C}\right)$ & References \\
\hline 1 & River Tamarind Seeds & 76 & 264 & This study \\
2 & Pomelo Waste & 60.3 & 235 & García et al. (2016) \\
3 & Oil Palm Biomass & 88 & 273 & Haafiz et al. (2014) \\
4 & Isora Fibre & 90 & 284 & Chirayil et al. (2014) \\
5 & Sweet Potato Residue & 72.5 & 258 & García et al. (2016) \\
6 & Coconut Husk & 65.9 & 241 & García et al. (2016) \\
7 & Banana Fibre & 74 & 255 & Cherian et al. (2008) \\
\hline
\end{tabular}

\subsection{The molecular weight of the cellulose nanocrystals}

Fig. 7 depicts the GPC chromatogram of CLLS and NLLS. Both celluloses peaked at 8.5 mins, which correlates with the retention time of cellulose $(9.2$ mins) observed by Haafiz et al. (2014).
CLLS (14kDa) was found to have a lower molecular weight compared to NLLS $(11 \mathrm{kDa})$. Hydrolysation of the CLLS with sulphuric acid caused the cleaving of the glycosidic bonds to remove the hemicellulose and lignin. This resulted in a lower molecular weight in NLSS as only the crystalline molecules remained in the structure.

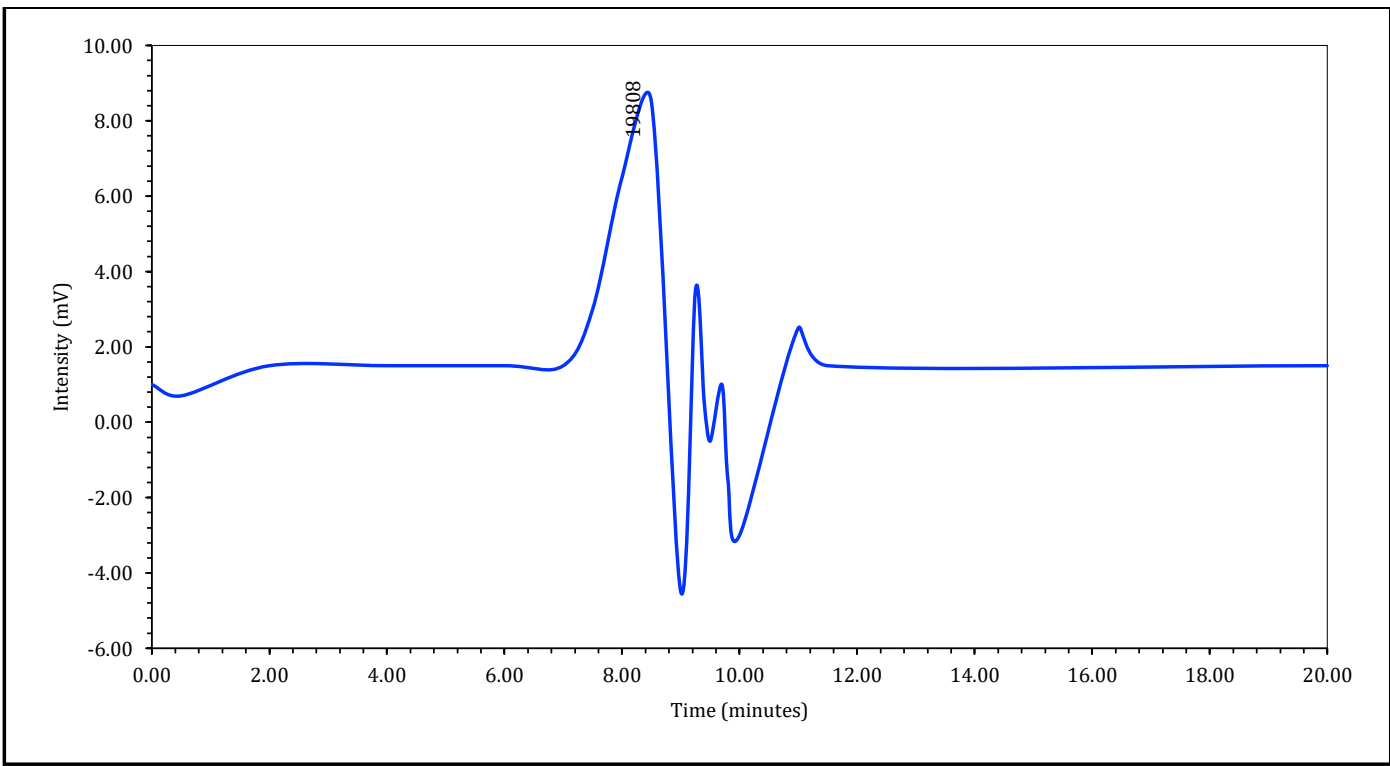

(a) 


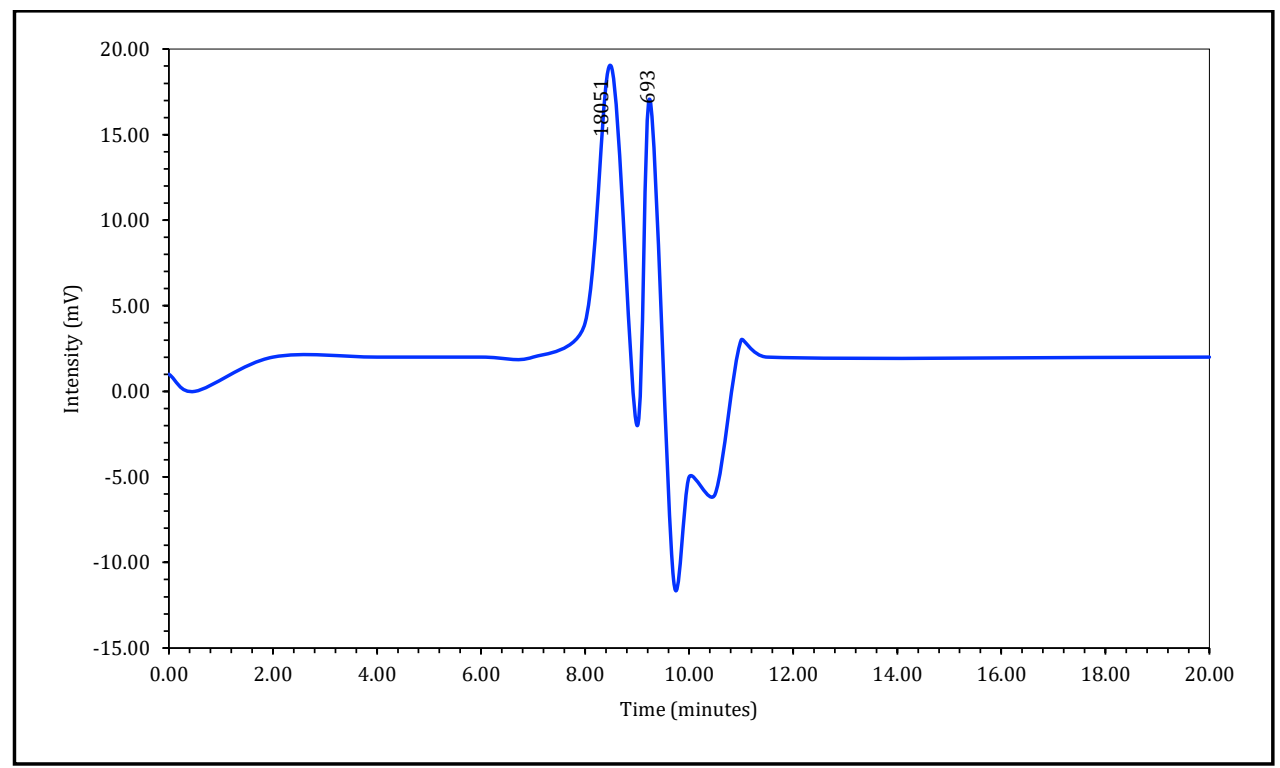

(b)

Fig. 7: GPC of (a) cellulose and (b) cellulose nanocrystals

\section{Conclusion}

Cellulose nanocrystals have been known to have various potentials to be used in industries. They are commonly derived from abundant and underutilized sources, cheap, biocompatible and biodegradable. These make them attractive sources to be employed as nanocomposites. Insoluble waste from the mature seeds of Leucaena leucocephala (LLS) is one of the underutilized nanocellulose sources with the potential to be optimized as nanocomposites. In this study, a preliminary synthesis method for producing cellulose nanocrystals for use on an industrial scale has been explored. However, in future work, optimization of the parameters, including acid concentration, should be studied.

It was successfully shown that a two-step acid hydrolysis extraction of LLS is able to produce cellulose nanocrystals. The two-step acid hydrolysis is able to reduce the amount of cellulose degraded throughout the process. LLS yielded $27 \%$ of cellulose nanocrystals with the thermal stability of $273.6^{\circ} \mathrm{C}$ and a crystallinity index of $75.9 \%$. FTIR analysis confirmed that most hemicellulose and lignin were removed during the acid hydrolysis. GPC analysis showed that the molecular weight of cellulose decreased after sulphuric acid hydrolyzation due to the breaking down of hemicellulose and lignin in the structure of the cellulose. The results from this study showed the possible use of the insoluble residual waste or marc obtained during the isolation of galactomannan from Leucaena leucocephala seed (LLS) could be a feedstock for nanocellulose production by a two-step acid hydrolysis process.

\section{Acknowledgment}

The authors would like to thank the University of Malaya for research funding IIRG017B-2019 and ST006-2019.

\section{Compliance with ethical standards}

\section{Conflict of interest}

The author(s) declared no potential conflicts of interest with respect to the research, authorship, and/or publication of this article.

\section{References}

Abitbol T, Rivkin A, Cao Y, Nevo Y, Abraham E, Ben-Shalom T, and Shoseyov $O$ (2016). Nanocellulose, a tiny fiber with huge applications. Current Opinion in Biotechnology, 39: 76-88.

https://doi.org/10.1016/j.copbio.2016.01.002 PMid:26930621

Bano S and Negi YS (2017). Studies on cellulose nanocrystals isolated from groundnut shells. Carbohydrate Polymers, 157: 1041-1049.

https://doi.org/10.1016/j.carbpol.2016.10.069

PMid:27987804

Brendel O, Iannetta PPM, and Stewart D (2000). A rapid and simple method to isolate pure alpha-cellulose. Phytochemical Analysis: An International Journal of Plant Chemical and Biochemical Techniques, 11(1): 7-10.

https://doi.org/10.1002/(SICI)1099.

1565(200001/02)11:1<7::AID-PCA488>3.0.CO;2-U

Chen $\mathrm{C}$ and $\mathrm{Hu} \mathrm{L}$ (2018). Nanocellulose toward advanced energy storage devices: Structure and electrochemistry. Accounts of Chemical Research, 51(12): 3154-3165.

https://doi.org/10.1021/acs.accounts.8b00391

PMid:30299086

Chen YW, Lee HV, and Abd Hamid SB (2016). Preparation of nanostructured cellulose via $\mathrm{Cr}$ (III)-and $\mathrm{Mn}$ (II)-transition metal salt catalyzed acid hydrolysis approach. BioResources, 11(3): 7224-7241.

https://doi.org/10.15376/biores.11.3.7224-7241

Cherian BM, Pothan LA, Nguyen-Chung T, Mennig G, Kottaisamy $M$, and Thomas S (2008). A novel method for the synthesis of cellulose nanofibril whiskers from banana fibers and characterization. Journal of Agricultural and Food Chemistry, 56(14): 5617-5627. https://doi.org/10.1021/jf8003674 PMid:18570426

Chirayil CJ, Joy J, Mathew L, Mozetic M, Koetz J, and Thomas S (2014). Isolation and characterization of cellulose nanofibrils 
from Helicteres isora plant. Industrial Crops and Products, 59: 27-34. https://doi.org/10.1016/j.indcrop.2014.04.020

Fahma F, Iwamoto S, Hori N, Iwata T, and Takemura A (2010). Isolation, preparation, and characterization of nanofibers from oil palm empty-fruit-bunch (OPEFB). Cellulose, 17(5): 977-985. https://doi.org/10.1007/s10570-010-9436-4

García A, Gandini A, Labidi J, Belgacem N, and Bras J (2016). Industrial and crop wastes: A new source for nanocellulose biorefinery. Industrial Crops and Products, 93: 26-38. https://doi.org/10.1016/j.indcrop.2016.06.004

George J and Sabapathi SN (2015). Cellulose nanocrystals: Synthesis, functional properties, and applications. Nanotechnology Science and Application, 8: 45-54. https://doi.org/10.2147/NSA.S64386 PMid:26604715 PMCid:PMC4639556

Haafiz MM, Hassan A, Zakaria Z, and Inuwa IM (2014). Isolation and characterization of cellulose nanowhiskers from oil palm biomass microcrystalline cellulose. Carbohydrate Polymers, 103: 119-125.

https://doi.org/10.1016/j.carbpol.2013.11.055

PMid:24528708

Han MD, Han JS, Hyun SH, and Shin HW (2008). Solubilization of water-insoluble beta-glucan isolated from Ganoderma lucidum. Journal of Environmental Biology, 29(2): 237-242.

Henrique MA, Silvério HA, Neto WPF, and Pasquini D (2013). Valorization of an agro-industrial waste, mango seed, by the extraction and characterization of its cellulose nanocrystals. Journal of Environmental Management, 121: 202-209. https://doi.org/10.1016/j.jenvman.2013.02.054 PMid:23542530

Husin M, Li AR, Ramli N, Romli AZ, Hakimi MI, and Ilham Z (2017). Preparation and characterization of cellulose and microcrystalline cellulose isolated from waste Leucaena leucocephala seeds. International Journal of Advanced and Applied Sciences, 4(3): 51-58.

https://doi.org/10.21833/ijaas.2017.03.009

Husin M, Rahim N, Ahmad MR, Romli AZ, and Ilham Z (2019). Hydrolysis of microcrystalline cellulose isolated from waste seeds of Leucaena leucocephala for glucose production. Malaysian Journal of Fundamental and Applied Sciences, 15(2): 200-205. https://doi.org/10.11113/mjfas.v15n2.1165

Ilham Z and Nimme FH (2019). Quantitative priority estimation model for evaluation of various non-edible plant oils as potential biodiesel feedstock. AIMS Agriculture and Food, 4(2): 303-319. https://doi.org/10.3934/agrfood.2019.2.303

Jiang F and Hsieh YL (2015). Cellulose nanocrystal isolation from tomato peels and assembled nanofibers. Carbohydrate Polymers, 122: 60-68.

https://doi.org/10.1016/j.carbpol.2014.12.064

PMid:25817643

Jonoobi M, Harun J, Tahir PM, Shakeri A, SaifulAzry S, and Makinejad MD (2011). Physicochemical characterization of pulp and nanofibers from kenaf stem. Materials Letters, 65(7): 1098-1100. https://doi.org/10.1016/j.matlet.2010.08.054

Jorfi M and Foster EJ (2015). Recent advances in nanocellulose for biomedical applications. Journal of Applied Polymer Science, 132(14): 41719. https://doi.org/10.1002/app.41719

Karimi K and Taherzadeh MJ (2016). A critical review of analytical methods in pretreatment of lignocelluloses: Composition, imaging, and crystallinity. Bioresource Technology, 200: 1008-1018.

https://doi.org/10.1016/j.biortech.2015.11.022

PMid:26614225

Khalil HA, Davoudpour Y, Islam MN, Mustapha A, Sudesh K, Dungani R, and Jawaid M (2014). Production and modification of nanofibrillated cellulose using various mechanical processes: A review. Carbohydrate Polymers, 99: 649-665. https://doi.org/10.1016/j.carbpol.2013.08.069 PMid:24274556
Kim JS, Lee YY, and Kim TH (2016). A review on alkaline pretreatment technology for bioconversion of lignocellulosic biomass. Bioresource Technology, 199: 42-48. https://doi.org/10.1016/j.biortech.2015.08.085 PMid:26341010

Li Y, Pickering KL, and Farrell RL (2009). Analysis of green hemp fibre reinforced composites using bag retting and white rot fungal treatments. Industrial Crops and Products, 29(2-3): 420-426. https://doi.org/10.1016/j.indcrop.2008.08.005

Lin N and Dufresne A (2014). Nanocellulose in biomedicine: Current status and future prospect. European Polymer Journal, 59: 302-325.

https://doi.org/10.1016/j.eurpolymj.2014.07.025

Lu Q, Cai Z, Lin F, Tang L, Wang S, and Huang B (2016). Extraction of cellulose nanocrystals with a high yield of $88 \%$ by simultaneous mechanochemical activation and phosphotungstic acid hydrolysis. ACS Sustainable Chemistry and Engineering, 4(4): 2165-2172.

https://doi.org/10.1021/acssuschemeng.5b01620

Mandal A and Chakrabarty D (2011). Isolation of nanocellulose from waste sugarcane bagasse (SCB) and its characterization. Carbohydrate Polymers, 86(3): 1291-1299. https://doi.org/10.1016/j.carbpol.2011.06.030

Marett J, Aning A, and Foster EJ (2017). The isolation of cellulose nanocrystals from pistachio shells via acid hydrolysis. Industrial Crops and Products, 109: 869-874. https://doi.org/10.1016/j.indcrop.2017.09.039

Mendes, DCCA, Ferreira NMS, Furtado CRG, and de Sousa AMF (2015). Isolation and characterization of nanocrystalline cellulose from corn husk. Materials Letters, 148: 26-29. https://doi.org/10.1016/j.matlet.2015.02.047

Morais JPS, Rosa MDF, De Souza Filho MDSM, Nascimento LD, Do Nascimento DM, and Cassales AR (2013). Extraction and characterization of nano-cellulose structures from raw cotton linter. Carbohydrate Polymers, 91(1): 229-235. https://doi.org/10.1016/j.carbpol.2012.08.010 PMid:23044127

Othman SH (2014). Bio-nanocomposite materials for food packaging applications: Types of biopolymer and nano-sized filler. Agriculture and Agricultural Science Procedia, 2: 296303. https://doi.org/10.1016/j.aaspro.2014.11.042

Pius A, Ekebafe L, Ugbesia S, and Pius R (2014). Modification of adhesive using cellulose micro-fiber (CMF) from melon seed shell. American Journal of Polymer Science, 4(4): 101-106.

Rabemanolontsoa H and Saka S (2016). Various pretreatments of lignocellulosics. Bioresource Technology, 199: 83-91. https://doi.org/10.1016/j.biortech.2015.08.029

\section{PMid:26316403}

Rahim N, Li AR, Kamarun D, and Ahmad MR (2018). Isolation and characterization of galactomannan from seed of Leucaena leucocephala. Polymer Bulletin, 75(5): 2027-2037. https://doi.org/10.1007/s00289-017-2135-7

Sèbe G, Ham-Pichavant F, Ibarboure E, Koffi ALC, and Tingaut $P$ (2012). Supramolecular structure characterization of cellulose II nanowhiskers produced by acid hydrolysis of cellulose I substrates. Biomacromolecules, 13(2): 570-578. https://doi.org/10.1021/bm201777j PMid:22260431

Segal LGJMA, Creely JJ, Martin Jr AE, and Conrad CM (1959). An empirical method for estimating the degree of crystallinity of native cellulose using the X-ray diffractometer. Textile Research Journal, 29(10): 786-794. https://doi.org/10.1177/004051755902901003

Smyth M, García A, Rader C, Foster EJ, and Bras J (2017). Extraction and process analysis of high aspect ratio cellulose nanocrystals from corn (Zea mays) agricultural residue. Industrial Crops and Products, 108: 257-266. https://doi.org/10.1016/j.indcrop.2017.06.006

Tibolla H, Pelissari FM, Rodrigues MI, and Menegalli FC (2017). Cellulose nanofibers produced from banana peel by enzymatic 
treatment: Study of process conditions. Industrial Crops and Products, 95: 664-674.

https://doi.org/10.1016/j.indcrop.2016.11.035

Xie H, Du H, Yang X, and Si C (2018). Recent strategies in preparation of cellulose nanocrystals and cellulose nanofibrils derived from raw cellulose materials. International Journal of Polymer Science, 2018: 7923068.

https://doi.org/10.1155/2018/7923068 